\title{
Politics, Responsibility and Adult Victims of Childhood Sexual Abuse
}

\author{
by Jo Woodiwiss \\ University of East Anglia \\ Sociological Research Online, Volume 12, Issue 2, \\ < http://www.socresonline.org.uk/12/2/woodiwiss.htm/> \\ doi:10.5153/sro. 1404
}

Received: 6 Oct 2005 Accepted: 7 Aug 2006 Published: 30 Mar 2007

\begin{abstract}
This paper will explore ways in which self identified survivors of childhood sexual abuse and false memory syndrome appropriate therapeutic discourses which both encourage women to hold themselves responsible for their own unhappiness and provide a way to alleviate that responsibility. Although I look critically at women's engagement with abuse narratives the intention is not to enter the 'recovered memory wars' but rather to explore the consequences of locating adult victims of childhood sexual abuse within a therapeutic rather than a political framework. Within this therapeutic culture priority is given to self-actualisation and personal fulfilment and the self is increasingly seen as a project to be worked on. A pervasive theme within the therapeutic literature is a particular linkage between women's 'inferiority' and their oppression. Women are not only shown an array of problems from which they suffer together with self-improving solutions but are encouraged to seek the 'hidden' causes of these problems in the past and to probe further and further back rather than look to the material conditions of their adult lives for explanations. Drawing on interview material I will look at how women invest in discourses which provide an explanation for hidden knowledge of abuse and may offer a way to alleviate responsibility but which also encourage them to (re)construct themselves as sick, damaged and ultimately responsible for their own unhappiness.
\end{abstract}

\section{Keywords: Childhood Sexual Abuse, Memory, Inner Child, Responsibility, the Self, Narrative}

Introduction

The marriage of feminism and the phenomenally popular recovery movement is arguably the most disturbing (and potentially influential) development in the feminist movement today (Kaminer 1993 quoted in Armstrong 1996:213-4)

1.1 Set against the background of the 'recovered memory wars' this paper is based on an ESRC funded research project which explored women's engagement with narratives of childhood sexual abuse, recovery and therapeutic discourses and the role that women themselves play in the construction and use of abuse narratives, whether by their own definition they have 'continuous', 'recovered' or 'false' memories of childhood sexual abuse. The one unquestioned truth within the recovered memory wars is that sexual abuse in childhood is a devastating experience which leaves a devastating mark on its victims. There is as Bass and Davis tell us 'no positive or neutral experience of sexual abuse' (Bass and Davis 1988:316). It is this belief that enables the identification of symptoms in the lives of adult women (Woodiwiss 2005a, 2005b, 2006).

1.2 The memory wars are themselves set against the background of a therapeutic culture (Furedi 2004) in which the reflexive self is seen as a project to be worked on (Giddens 1991). Within this culture we are encouraged to engage with therapeutic and self-help literature and to reconstruct ourselves as damaged and in need of healing (Furedi 2004). It is against this background that women, and it is primarily women, engage with a particular aspect of the body of knowledge surrounding CSA, recovery and healing that constitutes the 'harm story' (O'Dell 2003) and its therapeutic corollary, the 'healing discourse' (Davies 1995).

1.3 This is a story of psychological damage in which child sexual abuse is said to be so (inevitably) damaging that the effects, or symptoms, could be seen in adulthood. The identification of symptoms is particularly significant as it enables women with no memories or knowledge of sexual abuse in childhood to recognise themselves in the child sexual abuse narrative and to re write their own personal stories to 
include such a history (Woodiwiss 2005a, 2005b). By the 1990s the harm story had become so firmly established that the voices of those women whose stories did not conform found themselves silenced (Armstrong 1996, Woodiwiss 2005a, 2005b) and their stories, at least those aspects which deviated from the 'true' story, dismissed.

1.4 Central to the harm story of childhood sexual abuse are models of childhood and development which lay the foundations for the creation of a narrative that constructs women as psychologically damaged and vulnerable to further or repeated victimisation. This storying of the harmfulness of childhood sexual abuse through a discourse of development helps to position the victims of such abuse as remaining the product of their experiences of abuse (O'Dell 2003). Women are told:

Inside every adult who was sexually abused are the feelings of the little child she once was. That little girl is still frightened, confused and crying - waiting to be comforted by parents who will never come for her...That child needs to be reached, needs to be comforted, needs information about what has happened to her (Parks 1990:48).

1.5 Many survivors have difficulty with the concept of the child within. They are advised 'You may feel split, caught in a real schism. There is the 'you' that's out there in the 'real' world, and then there's the child inside you who is still a frightened victim' (Bass and Davis 1988:111). Dinsmore suggests that the adult woman 'purchase a doll, a symbol of her inner child, to be nurtured' (Dinsmore 1991:79). Others suggest women hold parties for their inner children, play games and have their husbands read them bedtime stories (Bass and Davis 1988, Dinsmore 1991, Parks 1990) There are also Internet sites with chat rooms solely for inner children and inner babies.

1.6 The inner child of the recovery movement and therapeutic literature is defined as much by what she is not as by what she is and central to this is the idea of a powerful, adult woman. Based on a utopian version of reality women are seen as having the right to individual happiness and success, needing only the ability to exercise their own inner power to claim this right. Whilst women who were sexually abused in childhood may well grow up to be 'guilt-ridden, self-sabotaging, sexually dysfunctioning, on-going victims' (Parks 1990:13) the adult women who were not sexually abused will grow up to thrive. Thriving here meaning 'enjoying a feeling of wholeness, satisfaction in your life and work, genuine love and trust in your relationships, pleasure in your body' (Bass and Davis 1988:20). The mature, healthy adult woman identified in much of the therapeutic literature can access her inner power and live a happy, fulfilled and successful life. Failure to do so is seen, not as a result of the social, economic and political conditions which delimit their possibilities (Kitzinger 1993, Tavis 1992), but as the result of abuse (Bass and Davis 1988, Dinsmore 1991, Blume 1990, Fredrickson 1992).

1.7 The sexual abuse recovery literature is aimed at women who believe they have been sexually abused in childhood and it offers a way to overcome or heal from the effects of that abuse. However, much of the literature is aimed at those who have no memories of sexual abuse and, based on the belief that the effects of sexual abuse can be seen in the lives of adult victims, this literature encourages women who are unhappy or disaffected with their lives to look for evidence of sexual abuse. The majority of women who, without continuous memories, come to believe they were sexually abused as children are unlikely to recover 'recall' memories (Bass and Davis 1988, Dinsmore 1991). However, memory 'is not needed for the survivor to begin the acknowledgement process' (Dinsmore 1991:56) or even the healing process as 'one does not need memory to heal from abuse' (Dinsmore 1991:65). Nevertheless, believing the abuse really happened and that it really hurt you is a vital part of the healing process (Bass and Davis 1988, Blume 1990, Dinsmore 1991, Fredrickson 1992).

1.8 Women who have no memories or knowledge of sexual abuse but who are unhappy or dissatisfied with their lives and looking for answers are encouraged to identify 'symptoms' of sexual abuse in their adult lives. These are seen as evidence of either a damaged inner child or a damaged, and therefore childlike, psychology which is said to exert an unhealthy influence on their adult selves. Women who entered adult life knowing they had been sexually abused as children are encouraged to reinterpret their lives and attribute the 'symptoms' to the sexual abuse they experienced in childhood. They must also revisit their childhoods and reinterpret not only their experiences of abuse but also the lessons they may have learnt from those experiences. Feminist research has shown the variety of ways that children and women experience, cope with, resist and survive sexual abuse (Armstrong 1996, Kelly 1988, Kirkwood 1993, Kitzinger 1993, O'Dell 2003, Woodiwiss 2005a, 2005b). However, within much of the self-help literature there is a failure to recognise the 'other side of being a victim' (Kelly 1988), within which it is hard to acknowledge the ways women might have resisted or the positive lessons they might have learnt (Woodiwiss 2005b).

1.9 So firmly established is the harm story that the perceived effects of sexual abuse, when located in the alternative reality promoted by the self-help/self-development literature, are seen as evidence even in the 
lives of those who have no memories or knowledge of such abuse. One of the most popular self-help manuals, The Courage to Heal (Bass and Davis 1988), lists over 70 symptoms of CSA. These include:

\author{
Do you feel powerless like a victim? \\ Do you have a hard time nurturing and taking care of yourself? \\ Are you able to enjoy feeling good? \\ Do you feel unable to protect yourself in dangerous situations? \\ Have you ever experienced repeated victimization (rape assault, battery) as an adult? \\ Do you have trouble feeling motivated? \\ Can you accomplish things you set out to achieve? \\ Do you feel you have to be perfect? \\ Are you comfortable with anger? Sadness? Happiness? Calm? \\ Do you have a hard time loving and accepting you body? Do you feel at home in it? \\ Do you often feel taken advantage of? \\ Do you find your relationships just don't work out? \\ Can you say no? \\ Do you often have sex because you want to, or only because your partner wants it? \\ (Bass and Davis 1988:35-38).
}

1.10 In addition to checklists much of the literature contains suggestions of how victims of sexual abuse are likely to feel. Dinsmore suggests victims may experience chronic depression, drug and alcohol abuse, anxiety, suicide attempts and a history of revictimization (Dinsmore 1991). These women, say Bass and Davis, are 'trained to be victims' and 'programmed to self-destruct' (Bass and Davis 1988). Those with no 'recall memory' are advised that their 'repressed memories' will 'stalk your unconscious and hamper your life with their aftermath' (Fredrickson 1992:24). In her survivors' after effects checklist Blume (1990) lists 'Denial: no awareness at all' and Fredrickson suggests that 'profound disbelief is an indicator that memories are real' (Fredrickson 1992:171). Whether or not it takes the form of checklists, identifying symptoms and making connections between adult and childhood experiences is central to the sexual abuse recovery literature. Through the identification of symptoms significance is conferred on earlier events which help to make the 'plot' appear inevitable (Lawler 2002). However, the 'symptoms' found in these checklists are applicable to a large cross section of women (Showalter 1997, Tavris 1992).

1.11 The therapeutic corollary to the harm story is the 'healing discourse' (Davies 1995), based on the same models of childhood and development. Together the harm story and the healing discourse encourage women to view themselves as sick, damaged and ultimately responsible for their own unhappiness and well-being. Within these discourses it is said women who were sexually abused in childhood do not grow up to be healthy adults (Bass and Davis 1988, Blume 1990, Contratto and Gutfreund 1996, Dinsmore 1991, Fredrickson 1992, Herman 1992, Parks 1990, Whitfield, 1987, 1995). Healing is designed to enable them to do so. Women are encouraged to contact an inner child or damaged child like part and learn to parent her in order that they may 'grow up' to become the powerful strong women they would, or even should, have been had they not been sexually abused (Ainscough and Toon 1993, Bass and Davis 1988, Dinsmore 1991, Parks 1990). For victims of sexual abuse time is said to have stopped still and so the adult victim can return to the point at which the abuse is believed to have occurred and, with the help of trusted friends and therapists, she can grow up without the damaging psychological effects of having been abused (Ainscough and Toon 1993, Bass and Davis 1988, Dinsmore 1991, Parks 1990).

1.12 There is now a large collection of literature aimed at adult victims of childhood sexual abuse, whether or not they have continuous or recovered memories. This research aimed to explore women's engagement with such literature and therefore, whilst not suggesting that the literature I have focussed on represents the totality of sexual abuse recovery literature, it does represent the literature that the majority of the participants in this study engaged with.

\title{
The research
}

2.1 The memory wars have been raging for the last twenty years but largely missing from this debate has been the women themselves - those who come to recover memories of having been abused and those who, with continuous memories of abuse can also show 'the other side of being a victim' (Kelly 1988). Where they are present, women are constructed as weak, vulnerable and at the mercy of misguided therapists or the ongoing effects of sexual abuse. My intention is not to engage in the memory wars or to look at whether individual women's claims to have been abused are true or not. Rather, my intention is to look at women's engagement with these discourses and to explore the role they themselves play in constructing and reconstructing their own narratives in the process of understanding, making sense of and improving their own lives. Therefore it was important to include women who had, by their own definition, continuous, recovered or false memories of abuse. Whilst I needed to be aware of women's feelings and sensitive to their needs I also felt it was important to treat them with respect and recognise that they were often best 
placed to look after themselves or know what they needed. Although I was not in a position to offer them counselling or support I did offer to provide a list of counsellors or support groups in their area if they felt this would be of benefit. I also felt it important to not contribute to the negative construction of women who engage with discourses of sexual abuse as weak, vulnerable and incapable of making choices and protecting themselves.

\section{Recruitment}

3.1 I wanted to recruit participants from a number of different perspectives and experiences and to ensure they understood what their participation would entail. I therefore chose to write an article which included a call for participants to be published in two newsletters: Cisters' newsletter for victims of CSA; British false memory society (bfms) newsletter for victims of false memory syndrome (FMS). The Cisters article yielded thirteen responses, of whom two withdrew. The bfms newsletter yielded one response and was followed by a mail shot which yielded nine responses, most of whom it transpired did not read the newsletter, of whom five withdrew. A total of sixteen women participated in the research and of these five had continuous memories, six had recovered memories, and five had false memories of CSA. However, of the five who believed they had recovered false memories, three did not reject entirely the idea that they had been sexually abused in childhood only that the perpetrators were their fathers. The ages of the participants ranged from mid 20 s to mid 60 s and all but two were white. In terms of sexuality, twelve identified as heterosexual, one as lesbian, one as bisexual, one said 'gone off men' and one said she was ' $15 \%$ bisexual'. Of the sixteen, six were single, eight were cohabiting, and two were in relationships but not cohabiting.

\section{Methods}

4.1 I was interested in looking at how and why women came to engage with CSA, recovery and therapeutic discourses, why they might enter therapy or read self-help manuals, sometimes without knowledge of having been sexually abused, and the extent to which they accepted the ideas and concepts promoted within the healing and recovery literature. I also wanted to look at why some women might come to reject their abuse narrative and identify themselves as suffering from FMS. I therefore needed a method that would allow women to talk freely about their experiences. A pilot study also taught me that I needed an approach which precluded a focus on women's experiences of abuse but which allowed those experiences to be taken as given. I decided to adopt a two-stage approach using questionnaires followed by either an interview or written account - with the women being given the opportunity to choose.

4.2 The questionnaire was designed to provide some autobiographical details together with a brief outline of participants abuse, including, if known, their age, the time and place the abuse occurred and the perpetrator(s). It also asked about the therapeutic material they engaged with, including their use of selfhelp material, and established whether they had continuous, recovered or false memories. The questionnaires enabled women's abuse histories to be taken as given, leaving the interviews to focus on healing and recovery. I hoped this would also reassure those who did not want to talk about their abuse.

4.3 I then used in-depth, semi-structured interviews based on a small number of open-ended questions that would allow follow up questions and prompts. This also had the flexibility to be used as guidelines for those who had chosen to provide a written account. The interview schedule was designed to encourage a conversational style in which women were able to talk more freely than if responding to rigid questions (Burgess 1982, 1984, Whyte 1982), and allowed them to determine the nature and depth of their responses. I also drafted two interview structures/written account guidelines: one for self-identified victims of CSA and one for self-identified victims of FMS. Women were asked about their lives and what led them to engage with the sexual abuse recovery literature, their experiences of therapy / counselling and their experiences of self-help literature. They were asked what they thought of the ideas and concepts found within this literature (such as the inner child, traumatic forgetting and alternative memories) and what they found helpful and unhelpful. They were also asked what influence if any they thought their history of CSA had on the person they are today. Those who believed they had recovered false memories of CSA were asked abut their experiences up to and including when they had believed they were victims of CSA as well as how they came to reject these memories and how these experiences might have influenced the person they are today.

4.4 The interviews themselves lasted between two and six hours, were tape-recorded and later transcribed. One of the most notable aspects of the interviews was the matter of fact way in which ideas and concepts which, in other circumstances, might be considered strange or even bizarre were discussed. Anne, for example, shared her life with a number of 'alters' and although it was only her front person who spoke she often used the pronoun 'we'. Sharing her life with upwards of twenty personalities, some of whom had personalities of their own, involved for Anne many of the 'normal' or everyday elements that we might associate with such relationships. It did not seem out of place or strange therefore when she made 
reference to her inner children, showed me cards and presents she had brought for them and discussed what activities they might do together. They were as much a part of her life as external friends might be to others and, when not talking about their traumatic experiences, this was how she referred to them. Fiona also talked about her inner child and the activities she might engage in. Although she did seem to be aware that it might be considered strange to others, her accounts described everyday activities that helped her cope with the stresses and strains of normal living.

4.5 The research process can be a welcome, and for some their only, opportunity to talk about their engagement with therapeutic literature and to revisit and assess their previous experiences and understandings. In addition it can be used to explore or articulate concerns they may have and test out responses to different ideas. A number of women commented that they were able to discuss issues and concerns in the interview that they had wanted but been unable to discuss elsewhere.

\section{How and why then do women engage with the sexual abuse recovery literature?}

5.1 The simple answer is that for many women a history of sexual abuse helps them to make sense of their lives and their present unhappiness or distress. In addition, as the harm story and the healing discourse locate not only the cause of but also the solution to such problems within the minds of individual women, they also promise empowerment and a better life. Like other areas of self-help literature unhealthy, adult women may be constructed as the cause but the healthy adult woman is constructed as the solution. The recovery literature promises women a way to achieve this.

5.2 Whether they had continuous memories or not the reason women entered therapy and/or read self help books was because they were unhappy with at least some aspect of their lives. For the majority of women, particularly those who entered adulthood with no memory, the harm story was one that they were happy to accept, or perhaps needed to accept. It is this story which enables them to make the connection between present unhappiness and past/childhood trauma. This in turn allows them to reconstruct their sense of self and re write their own personal narratives within a framework of childhood sexual abuse which accords them at least some autobiographical certainty:

The clues were all there when you look back with hindsight. I was not quite the same as everyone else (Angela)

There were lots of things that I suddenly thought about, that's why that's like that and it all slotted into place suddenly. It wasn't just the children that I worked with that were abused it was me as well (Rae)

Not all those with continuous memories connected their abuse with difficulties or unhappiness they experienced in adulthood but others saw a clear connection to childhood experiences:

It was more a case of feeling (as I have and will probably always feel) as though because of the abuse, there was something not right, something missing from me, that perhaps I may be able to find in a book (Emma)

5.3 Other women had no idea of the cause of their unhappiness. Beccy had negotiated her way through a whole range of self-help material before being introduced to recovery literature by her therapist. Although benefiting from material such as that relating to diet she found the answer to her problems in the pages of Secret Survivors (Blume 1990) a self-help text, that her therapist introduced:

there's a checklist at the beginning with all sorts of questions. She was hiding the cover because obviously she didn't want to lead me into believing anything that, you know, she's not trying to say "Oh that's what happened to you", she never did. It all came out because it was. But she took me through the checklist and l'm saying yes, no, yes, no, yes, no, yes, no and she said ok. Well this is the book and you've got most of the answers correct so maybe have a read and see how you feel about it. So that was the first one really that I read. When I read it I still didn't have any memories then but I went yes, I mean if that's what happened that would explain it so much. That would really completely make sense but I still didn't have any memories then. (Beccy)

\section{How to be 'normal'}

6.1 The idea of normality was a recurring theme in women's accounts of healing and recovery. The idea that they were or might be reacting normally to an abnormal experience was one that women found to be very helpful and reassuring. For some it explained why they were the way they were whilst for others it offered a reason why they need not change, at least until they were healed. At least within the recovery community they were able to perceive themselves as normal. 
6.2 Women who entered adulthood with continuous memories readily identified themselves as different from those who had not been abused, particularly in terms of relationships and trust. Julie visited a Parks Inner Child Therapist (PICT) specifically to deal with her experiences of sexual abuse:

What I got from it more than anything was that I'm quite normal because I felt abnormal. It seems abnormal that it had happened but it was quite a relief to me really (Julie)

However, it was not only those women with memories who felt abnormal or different:

To have such an explanation. Yes definitely, yes it did. Because I was normal, I wasn't some kind of freak, then it was normal. The reason why, the reason I had problems was because something really bad happened and it made sense and I'm not some kind of weirdo then, I'm just normal. (Beccy)

There's nothing peculiar or weird about you. She would tell me this is o.k. uncomfortable, difficult to work with but its kind of normalish (Fiona)

6.3 Although the sexual abuse recovery literature contributed to increased levels of self-esteem and feelings of normality among women it could be used to the opposite effect, particularly by others. During her first period of counselling Emma believed the recovery literature had helped her to construct a sense of self as positive and normal. However, the second of period of counselling, which followed a miscarriage, she felt contradicted this first period. Although she recognised that she was unhappy following her miscarriage she rejected the connection made between this and her abusive childhood. For Emma a miscarriage was a 'real' problem which would be distressing and difficult for any woman to deal with:

I think the important difference between the two sessions was that the first time, I really did need to talk about what had happened, to make me understand that I was normal. But the second lot of sessions years later seemed so negative because I felt, she was trying to tell me that I was abnormal and always would be because of my childhood. (Emma)

6.4 The counsellor, she felt, drew on the recovery literature not to reinforce her feelings of normality but rather to construct her as abnormal and position her within a therapeutic framework in which her reactions to events, rather that the events themselves, were seen as problematic. CSA as a causal narrative was used by her counsellor to dismiss external factors and to construct the problem in terms of Emma's damaged psychology which resulted from sexual abuse in childhood.

6.5 Not all the women in this study were 'the first author of the story' (de Rivera 1998) and for these women the idea that they had a history of CSA was one that was first put to them by someone else. Three of these women entered a form of hypnotherapy to address physical conditions (two to lose weight, one to alleviate ME type symptoms) and whilst they were not the first author the idea that they had ME or a weight problem because they were unhappy with their lives was one that made sense to them:

She believed she had to uncover something yes because she felt I didn't feel good about myself and so she had to find out why I didn't feel good about myself (Rae)

he said to me because I wasn't losing weight there was a reason why I wasn't losing weight and it all went back he said to my childhood. He said we'll regress and we'll go back and see what the reasons were. (Hazel)

6.6 When the hypnotists drew on this understanding and suggested they need to discover what was causing their unhappiness they were tapping into ideas that resonated to some extent with the women's own belief systems. These included the idea of knowledge stored in the unconscious mind and could therefore accommodate the idea of memories or knowledge held by an inner child or damaged child like part of their adult selves.

\section{The inner child}

7.1 For many women the influence of an inner child, evidenced by an array of symptoms which they are encouraged to identify and attribute to sexual abuse in childhood, represents their first introduction not only to the concept of an inner child but more specifically to their own inner child. In attempting to make sense of and improve their lives it is the aspect of the inner child who influences the adult woman that women are likely to come across first. Therefore, before they acknowledge an inner child and develop or establish a relationship with her they have already accepted the idea and in doing so may have brought her a step closer to reality. However, accessing knowledge is not the only reason women develop a relationship with an inner child. 
7.2 The concept of the inner child is one which the majority of women accepted and of those who did, not all were limited to only one. Anne, for example, had identified hundreds of alters and had already developed relationships with over twenty of them and Fiona contemplated additional therapy to help her contact another inner child who she thought might hold knowledge of her abuse. Others, such as Jay, found the concept troubling and potentially dangerous, a view also shared at times by Beccy and Fiona.

7.3 How women understood the concept of an inner child, who or what they thought she was and the ways if any they made use of her varied considerably and again showed that the way women negotiated these discourses was more sophisticated and thoughtful than they have often been credited with. For some she was a means through which they could express feelings and emotions whereas for others she was much more real than this. For these women it was not the adult woman who was expressing feelings and emotions but those feelings were seen to come direct from an inner child. Fiona for example often found herself in a situation where it was her inner child and not her adult self who was reacting to some situations:

I was quite often being very upset if we had a conflict. The first few times it happened I was so caught up in it I couldn't make any sense of it but then I was able to take a step back and try and think about what was going on. It was then that I started to think well how am I feeling when this is happening, what's going on in my head because I'm not here and I'm not now. I'm not feeling like I'm in my own house and that I'm 37 years old, what am I feeling like and I felt like I was a young child and I was lost (Fiona)

An alternative reading of the inner child is provided by Beccy:

Yeh, I mean I don't really see it as separate. I see it as err... I mean it's me, she was me. That's me how I was. It's not me that I can see it separate (Beccy)

7.4 Whilst Beccy does not view her inner child as separate she does believe that there is a part of her that influences the thoughts and behaviours of her adult self. It is this part of her adult self, very similar to the inner child of Fiona's, that has the knowledge of abuse and which takes over at times of distress or difficulty:

Say if I'm in bed with my partner and I get emotional flashbacks I'm not reacting to what's happening in bed with my partner, I'm reacting to what happened to me as a child. Which means this part of my mind that's causing the emotional flashbacks is still emotionally a child. It hasn't worked it through and developed so in a way it's getting in touch with that part of my mind that's still reacting to what happened. So yes I see it as part of my mind rather than something separate. (Beccy)

7.5 Both women draw on the same discourses of healing, recovery and the inner child but apply them in ways that best suit themselves and their situations. However, although she makes it very clear that the inner child is not separate Beccy does confer a level of autonomy and control on the child part of herself that at times is not dissimilar to the level of control said to be exercised by the inner child of Fiona.

7.6 Although Jay rejected the inner child she had nevertheless found a way of making her work for her:

I think for me it was looking at other children who were the same sort of age as when I was abused because I did blame myself. I found looking and talking to children of that age then I found it more and more difficult to say well it was me encouraging him, it was me being a flirt because I kept thinking well at that age I shouldn't have understood.... So I suppose you could use inner child as err, looking at it a bit differently but I looked at it that way. (Jay)

7.7 One of the criticisms of the healing discourse and inner child work is the way it can infantilise women (Armstrong 1996). The literature does encourage women to engage in childish/children's activities and at times to 'become' a child but women use this advice in ways that best suit them and their needs. Whilst Beccy did not see her inner child as separate she did identify in her the means by which she could work on different aspects of her life or personality. For her the inner child represented a way in which she (her adult self) could learn to enjoy life more. However, it was not something which came easily to her:

I only give $100 \%$ if it's real. I can't do it if it's pretend. It's something I have to work through as well. [Why?] Because I need to be able to play, I want to be able to play. I want to be able to erm... to go into an imaginary world and really feel things when I want to. Not just plough through the not so good everyday things that I have to do. (Beccy)

7.8 Whereas the inner child was used by Beccy to represent a part of her adult self for others such as Fiona and Anne the inner child (or children in Anne's case) was more real or separate. However, this 
understanding is not always unambiguous or clear-cut, which itself may relate to how contact with the inner child is seen by women as a way to help their adult selves. As the following exchange shows, although Fiona recognised or identified her inner child as separate, she also used her as a way to engage in activities which she felt will benefit her adult self:

Looking after the inner child I think is more basic it's cuddling up with my teddy. I keep a teddy by my bed and if my inner child is feeling tearful and afraid l'll go to bed and cuddle my teddy and have a wee cry and that's how I take care of my inner child.

[But the teddy's not your inner child?]

No no

[It's just some books suggest you have a teddy as a...]

No my inner child is in me, not a separate part of me it's always me, actually me [So is it you cuddling the teddy for your inner child or is your inner child cuddling the teddy?] My inner child's cuddling the teddy. It's me as an adult telling myself to get into bed and cuddle the teddy and keep myself warm and have a wee rest and it's my inner child that's doing that, that's lying in the bed cuddling the teddy. When my inner child has been comforted, had a little cry, cuddled the teddy and I'm calm and it's my adult self that gets out of bed and carries on with the day. I'll look after my inner child as well with music. I actually like to dance about. If l've got the place to myself (laughs) not if my partner.... I'll put on music that I like and I'll have a wee dance about the place and just feel happy. Sometimes just to relax and feel happy and I do that when I'm on my own but not when I'm with anybody else. That part of me feels safest when it's just me and her.

[What if you want to dance?]

If I want to dance I would go with my friends out dancing or out with my partner out dancing but I would do that in the company of other people but erm, for that part of myself to be able to express her happiness and joy she would want to do that with just me there, not anybody else. Colouring in, I went through a period, not recently, but when I used to have a colouring in book and crayons and just lie on the floor and colour in. l'd feel quite calm and happy doing that. (Fiona)

7.9 The relationship Fiona developed with her inner child was not only influenced by the recovery literature but also by discourses of femininity and what she believed were the appropriate thoughts and behaviours of adult women. Although she acknowledged that some of the activities engaged in by her inner child were beneficial they challenged her perception of her self as a mature adult woman. The concept of an inner child enabled her to engage in certain pleasurable or beneficial activities without threatening this identity.

7.10 For Jay this was the wrong way round. She believed the concept was used to encourage women to believe that as healthy adult women they should not have certain feelings and therefore when they had such feelings they could not be attributed to a healthy adult woman. Whereas Jay was ready to challenge the construction of adult womanhood, which in turn made it easier to reject the concept of an inner child, this was perhaps not so easy for Fiona and Anne. These two women accepted such a construction but used the inner child as a way of mediating its effects on their own lives. However Jay believed it would be healthier for women to recognise and take responsibility for the way they felt and behaved:

I worried enough about whether I'm mental or not I don't want that. ... because you're trying to put yourself together and then you're being told to split yourself up again. It just didn't make any sense. I know sometimes you feel like a child and feel vulnerable and scared and everything else but are we not allowed to feel that as adults... Yeh I feel vulnerable now. That's what I have to deal with. I'm living now not then... (Jay)

7.11 Anne, the woman who identified hundreds of alters, developed relationships with her inner children that appeared to be much stronger than those of other women. Over many years Anne had come to identify first a history of CSA and then of ritual abuse. It was in her dreams that she first learnt she shared her inner world with hundreds of alters and also in her dreams that these inner children told her of the ritual abuse, although sometimes in a form that she needed help understanding.

7.12 Anne sees her inner children as very real and was the only one who often used the pronoun 'we' when talking. However, she also uses the inner child to engage in similar activities to those of Fiona. Although not all Anne's alters are people (a few are animals) of those that are all but one are girls and all display strict gender attributes. Of the girls she says at one point:

I've got a lot of very sweet little children, you know, who are delightful and great fun, sort of ingenious and l've tried to train them not to take sweets from strangers or go off with them ...(Anne) 
7.13 She writes poems to them and buys them presents and cards, an idea suggested in much of the literature but not taken up by others. In return they 'like colouring in books, they love glittery stuff, all the girly stuff. The girls who populate Anne's world display the feminine characteristics that she herself may be uncomfortable with. As she says: 'Because in my teenage years I had no intention of growing into a woman at all' (Anne). Whereas the inner child of Fiona's world helps her maintain the identity of a mature adult woman the inner children of Anne's world may help her to avoid such an identity.

7.14 The only boy among Anne's personalities conforms to a particular stereotype of (troubled/troublesome) male youth. He is also the one she seems to have the most affection for. He was the one "who had to be incredibly courageous...the daring one' (Anne). He first surfaced by a football ground and when he writes it is always using graffiti, 'you know stroppy kids kind of thing, you know, graffiti artist, tough graffiti artist...' (Anne).

7.15 The inner child need not always be the weak, vulnerable person evident in much of the literature but could also be used as a representative, or possibly a reminder, of happier times. In the case of Sarah literally a snapshot of when she was full of fun and laughter:

I have an inner child oh yes. Stay there l'll show you my photo of my inner child (Sarah leaves the room and returns with a photo) This is a photo I love, this is my inner child she's beautiful, just her face and the laughter it's brilliant. ... She's probably about four. She's brilliant yeh yeh. Full of fun and laughter, fantastic (Sarah)

7.16 Although contacting their inner child directed women to identify a weak and vulnerable part of themselves when combined with the idea of parenting it also helped some women to identify a stronger and wiser part:

It was very useful and I actually found myself being wiser than I realised I was. It was as if I was being able to tap into some wisdom that I had that I didn't even realise was in there when I was trying to parent my child. (Fiona)

\section{The problematic inner child and MPS}

8.1 Although the majority of women were introduced to the idea of an inner child or child like part not all found these concepts unproblematic or even useful. Even where they had developed a relationship with an inner child this was not necessarily without problems.

8.2 For Jay the knowledge of her abuse was clearly stored in the conscious mind of her adult self. However, she rejected the concept of the inner child not because she did not need her to verify an abusive history but because she came to believe her to be at times unhelpful and at times dangerous. She identified inner child work as central to the creation of multiple inner children or personalities and although her own experiences suggests it is possible to reject this work, this would not be easy particularly for someone for whom the inner child might represent their only chance of gaining knowledge of sexual abuse. One of the difficulties for Jay who had memories of abuse stretching over her whole childhood was to work out what age she would be or should she have more than just the one:

Yes it was multiple. And I was thinking I don't want to end up getting sectioned for having multiple personalities. ... They said no it's just sort of inner child work and I said no because if you're trying to acknowledge somebody at a certain age then you're looking at that person as an individual and to me that usually means looking at it and giving it personality or a name and something like that. Now if you have five or six or eight of them it's going to get rather crowded (Jay)

8.3 Although she found her inner child to be valuable Beccy also cautioned against identifying her as someone separate from the adult self. She used an example she found in the literature to illustrate her concerns:

I have read a book about someone who was emotionally abused by her mother and she has loads of children and she talks to them and she can be one or the other. That freaked me out slightly. I was like, oh I don't know. They're all you so is it good to be so separate? Like this one had that personality and this one had that one. I'm thinking what, they're all you. So I think there can be damage somewhere there of not integrating everything and not working through some things because you think, oh well that's not me that's that inner child there, or that inner child there. When really, it's all you (Beccy)

8.4 The danger for Jay and Beccy was the potential to create separate personalities during the course of therapy. Fiona, although not sure whether it was a problem or not, had also recognised that during the 
8.5 However they came into being, once real these children could take on a life of their own. This was very different to the concerns expressed by Anne who, as a multiple personality, had become used to existing 'as part of a group'. She believed her inner children were created at the time of trauma. Inner child work was problematic for Anne not because she did not identify with the idea or recognise her own inner child but rather because she recognised many, 'Because if a lot of us have got inner children, I mean who is going to be the inner child?' (Anne). Although she was the only woman who shared her life with a number of personalities the relationships Anne developed with them and the benefits she gets from sharing her life with them are not dissimilar to those of other participants.

\section{No improvements: what happens when it doesn't work?}

9.1 As the harm story and the healing discourse locate not only the cause but also the solution to women's unhappiness and dissatisfaction within the minds of individual women, they also promise empowerment and a better life. But what happens when they are no longer seen to work? Of those who participated in this study it could be said that six had not seen sufficient improvements in their lives as a result of coming to believe that they had been sexually abused as children. Of these five believed themselves to be the victims of False Memory Syndrome (FMS) and the sixth came to believe that she was not the victim of 'mere' incest but rather of a more traumatic form of childhood abuse. Although they rejected different aspects of an abuse narrative only two women rejected entirely the idea that they were victims of some form of abuse. The others, contrary to popular perceptions of false memory syndrome, believed they may have been sexually abused as children and it was only the aspect of the 'memory' which identified their fathers that they rejected, although even here they remained uncertain.

9.2 Women who came to believe they had been sexually abused as children but who later rejected these beliefs drew not only on the discourses around the harm story, traumatic forgetting and healing but also on the FMS discourse. As it constructs false memories as a form of abuse and therapists as the perpetrators of this abuse FMS provides women with a way to reject their abuse narratives without having to see themselves as responsible for them whilst also enabling them, should they wish or need to, to maintain an identity of victim. Of the five who believed their memories to be false only two used FMS to absolve themselves of all responsibility. Although they had at some point believed they were the victims of sexual abuse in childhood both these women now believed they were the victims not only of FMS but also of malicious therapists. The other three did not entirely reject the idea that they had been sexually abused, only that it had been perpetrated by their fathers. Therefore, although they believed their therapists were irresponsible and failed to recognise that 'false knowledge' could be recovered from the unconscious mind, they also believed that some of this knowledge did in fact relate to some form of sexual abuse. As such it could not have been implanted by a therapist. One of these women, who thought her abuse might have occurred in a past life, did at the same time recognise that her motivation for this belief may lie in her desire to maintain the positive image she had of her father. Although they had all at some time believed they were the victims of sexual abuse in childhood none of these women were the first author of their story. It may be this combined with a lack of improvements in their lives that led them ultimately to reject this history.

9.3 Anne also did not identify improvements in her life following her coming to believe she was the victim of childhood sexual abuse. Unlike those who came to reject their abuse histories Anne had invested heavily in a therapeutic solution to her unhappiness and was the first author of her story. For her, childhood sexual abuse as a causal narrative did not provide an adequate explanation for her unhappiness nor help her to make improvements in her life. For her the answer lay deep in her unconscious where she believed the knowledge of even greater trauma was stored. Her alters are not the 'happy little children and happy little adults' found in the incest literature but 'the totally traumatised children' (Anne) of ritual abuse. Incest she believes is 'milder' and she even refers to a time when she was 'just an incest victim' (Anne). Sharing her world with inner personalities is so much a part of Anne's life that in many ways it is her life - a life more real than the one outside. It may be that MPS has provided her with a new way to be unhappy (Hacking 1995) but I believe we should offer her more than that.

\section{Conclusion}

10.1 The role of therapists and self-help literature in the creation or surfacing of the inner child, along with the nature of recovered memories, is a central question within the recovered memory wars. Within this debate women are often constructed as passive victims of either CSA or of misguided or malicious therapists. However, the relationships women develop with an inner child or children are not as simplistic or as static as the debate would suggest. Whilst she has a certain uniformity within different strands of the literature, the inner child, or childlike part, of women's accounts is more fluid and women's engagement with her more critical, complex and pragmatic as they negotiate their own path through the literature. She may be more or less real, more or less childlike, more or less in control, depending on the needs, wishes and 
circumstances of the women who engage with her. For some she may not exist at all whilst for others she may be a useful tool or companion on their journey through life or to recovery. For others she may be the product of therapeutic techniques, such as inner child work, which can be perceived as both useful and dangerous. Whatever she is she is not, and cannot be, taken straight from the pages of the literature or imposed on women by external agencies but neither does she emerge fully formed from women's subconscious.

10.2 Whilst I have attempted to show that women are not simply passive victims, either of CSA or of misguided therapists, I do believe that the sexual abuse recovery literature, with its reliance on the inner child or child like part of the adult self, is or can be problematic. This literature, with its promotion of the inner child, reinforces the idea that there is a particular way for the healthy adult women to think, feel and behave. In doing so it not only constructs those women who do not conform to this stereotype as deviant, damaged and in need of healing but it prohibits such thoughts and behaviours except when engaged in from the secret or damaged position of an inner child.

10.3 As recovered memories and healing are tied up with the inner child, who is said to hold the knowledge of childhood abuse and be in need of healing, it may be that those who do not see sufficient improvements in their lives or find sufficient evidence from one inner child are likely to look deeper and deeper for more inner children who can furnish them with the knowledge they believe they need to explain their lives and heal. Although Anne was the only one to develop a relationship with many inner children, the idea that additional knowledge was stored deeper in their unconscious than was the knowledge they had so far accessed and which they might need to access in the future was one shared by a number of the participants. Some participants suggested that their lack of knowledge reflected the depth of their trauma. I would argue that those who were prepared to go down a route that might ultimately lead to the identification of additional children or alters, had already invested heavily in a therapeutic solution to their unhappiness or dissatisfaction. This is not to suggest that those who go down such a route are recovering 'false' memories on which they can base their narratives as such a path can be followed by those with continuous or recovered memories and I believe reflects a lack of certainty or a lack of improvement in their lives rather than a lack of 'truth'.

10.4 Not all those who participated in this study had invested heavily in a therapeutic solution. I believe that for those who had not made such an investment but who had also not seen sufficient improvements in their lives or their level of knowledge then a false memory discourse offered them a different route. Stuck in a kind of 'biographical limbo' (Tietjens-Meyers 1997) FMS offered these women a way to explain how they had come to construct and believe in a sexual abuse narrative which they might be starting to doubt, or want to reject. However, perhaps the most notable aspect of the abuse narratives of the women who participated in this study and who came to believe that their stories were based on false memories was that they were not the 'first author' of their narratives, unlike the other participants who believed they were the first authors.

$10.5 \mathrm{It}$ is also worth noting here that a belief in a history of CSA does not necessarily preclude the adoption or construction of a narrative based on FMS. Indeed three of the women who believed they had recovered false memories did not reject entirely the belief that they had been sexually abused in childhood but only that the perpetrator of that abuse had been their father. It could also be argued that continuous memories of CSA also need not preclude the adoption or use of a false memory narrative, which like MPS offers a way to move from a lack of certainty or improvements. For those who have not found happiness and success, whatever the status of their memories, FMS offers them a way to withdraw from an accusation of sexual abuse whilst to some extent maintaining an abuse narrative. For those still looking to explain or improve their lives this might be a valuable narrative device.

\section{Acknowledgements}

I would like to thank all those who have participated in this research, the ESRC who funded the project and the valuable comments from the referees.

\section{References}

AINSCOUGH, C and K Toon (1993) Breaking free: Help for survivors of child sexual abuse London: Sheldon Press

ARMSTRONG, L (1996) Rocking the cradle of sexual politics London: The Women's Press

BASS, E and L Davis (1988) The courage to heal London: Cedar 
BLUME, S (1990) Secret survivors: Uncovering incest and its aftereffects in women New York: Ballantine

CONTRATTO, S and M J Gutfreund (1996) 'Introduction' in Contratto, S and M J Gutfreund (eds) A feminist clinician's guide to the memory debate New York: Harrington Park Press

DAVIES, M (1995) Childhood sexual abuse and the construction of identity: Healing Sylvia London: Taylor and Francis

DINSMORE, C (1991) From surviving to thriving: Incest, feminism and recovery New York: State university of New York Press

DE RIVERA, J (1998) Evaluating Believed-in imaginings: in de Rivera, J and T Sarbin (1998) (eds) Believed in imaginings: The narrative construction of reality Washington DC: American Psychological Association

FREDRICKSON, R (1992) Repressed memories: A journey to recovery from sexual abuse New York: Fireside/Parkside

FUREDI, F (2004) Therapy culture London: Routledge

HACKING, I (1995) Rewriting the soul: Multiple personality and the science of memory Princeton:

Princeton University Press

HERMAN, J (1992) Trauma and recovery: From domestic abuse to political terror New York: Basis Books

KELLY, L (1988) Surviving sexual violence Cambridge: Polity Press

KIRKWOOD, C (1993) Leaving abusive partners London: Sage

KITZINGER, J (1993) 'Sexual violence and compulsory heterosexuality' in Wilkinson S and C Kitzinger (1993) Heterosexuality: A feminism and psychology reader London: Sage

LAWLER, S (2002) Narrative in social research in May, T (2002) (ed) Qualitative research in action London: Sage

O'DELL, L (2003) 'The 'harm' story in childhood sexual abuse: Contested understandings, disputed knowledges' in Reavey, P and S Warner (2003) (eds) New feminist stories of child sexual abuse: Sexual scripts and dangerous dialogues London: Routledge

PARKS, P (1990) Rescuing the inner child London: Souvenir Press

SHOWALTER, E (1997) Hystories London: Picador

TIETJENS-MEYERS, D (1997) 'The family romance: A Fin-de-Siecle Tragedy' in Nelson, H L (ed) Feminism and families London: Routledge

TAVRIS, C (1992) The mismeasure of women London: Touchstone

WHITFIELD, C L (1987) Healing the child within: Discovery and recovery for adult children of dysfunctional families Deerfield Beech, Fl: Health Communications Inc.

WHITFIELD, C L (1995) Memory and abuse: Remembering and healing the effects of trauma Deerfield Beech, FI: Health Communications Inc.

WHYTE, W (1982) 'Interviewing in the field' in Burgess, R (ed) Field research: a source book and field manual London: Allen and Unwin

WOODIWISS, J (2005a) Stories to live by, Selves to live with Unpublished PhD thesis University of York

WOODIWISS, J (2005b) '(Re)writing memories: Childhood sexual abuse and everyday life' in Kelly, $\mathrm{N}$ et al (eds) (2005) Narrative, memory and everyday life Huddersfield: University of Huddersfield Press

WOODIWISS, J (2006) 'Alternative memories: Searching for knowledge, telling a story' in Milnes, $\mathrm{K}$ et al (eds) Narrative, memory and knowedge Huddersfield: University of Huddersfield Press 